\title{
The Impact of the Morphologic Characteristics of Type B Aortic Dissection in the Acute Phase on the Aortic Enlargement in the Late Stage
}

\author{
Ken Nakamura, Tetsuro Uchida, Azumi Hamasaki, Mitsuaki Sadahiro \\ Second Department of Surgery, Yamagata University Faculty of Medicine, Yamagata, Japan \\ Email: ken.nakamura622@gmail.com
}

How to cite this paper: Nakamura, K., Uchida, T., Hamasaki, A. and Sadahiro, M. (2019) The Impact of the Morphologic Characteristics of Type B Aortic Dissection in the Acute Phase on the Aortic Enlargement in the Late Stage. World Journal of Cardiovascular Diseases, 9, 9-19. https://doi.org/10.4236/wjcd.2019.91002

Received: December 23, 2018

Accepted: January 19, 2019

Published: January 22, 2019

Copyright $\odot 2019$ by author(s) and Scientific Research Publishing Inc. This work is licensed under the Creative Commons Attribution International License (CC BY 4.0).

http://creativecommons.org/licenses/by/4.0/

\begin{abstract}
Objectives: According to the International Registry of Acute Aortic Dissection, $>70 \%$ of patients with type-B aortic dissection (AD) have delayed aortic growth. The objective of this study was to investigate the morphologic characteristics of aortic enlargement in type-B AD. Methods: A total of 120 patients with uncomplicated acute type-B aortic dissection (uATBAD) were divided into 4 groups according to the presence of a patent or thrombosed false lumen (FL) with or without aortic enlargement. In all groups, the area of the true lumen (TL) and the FL were measured on axial computed tomography images. Results: A total of 120 uATBAD patients were evaluated: patent FL with (PE, N $=28,23 \%)$ or without aortic enlargement (PU, $\mathrm{N}=17,14 \%)$ and thrombosed FL with (TE, $\mathrm{N}=34,28 \%$ ) or without enlargement (TU, $\mathrm{N}=41,34 \%$ ). The initial aortic diameter was not significantly different among the 4 groups (PE vs. $\mathrm{PU}=39 \pm 8$ vs. $37 \pm 10(\mathrm{p}=0.354)$; TE vs. $\mathrm{TU}=38 \pm 6$ vs. $37 \pm 6(\mathrm{p}=0.391))$. The area of the FL tended to be larger in the PE group. In contrast, the area of the TL was significantly larger in the TE group. Late outcomes of UATBAD treated with optimal medical treatment were acceptable. Conclusions: In patients with UATBAD and a thrombosed FL, the patients with aortic enlargement tended to be increased TL size. In contrast, in patients with a patent FL, the patients with aortic enlargement tended to be increased FL size.
\end{abstract}

\section{Keywords}

Uncomplicated Type B Aortic Dissection, Optimal Medical Treatment, Aortic Enlargement, Thoracic Endovascular Aortic Repair,

Chronic Aortic Dissection

\section{Introduction}

Acute aortic dissection is medical and/or surgical emergency. That usually re- 
sults from a tear in the aortic intima, which allows a pressurized hematoma to form within the media between external and internal intima. The blood in the false lumen is contained by only the thin outer third of the media and the loose adventitial connective tissue, rupture into the pericardial space, pleural cavity, or mediastinum is common. Surgical intervention is generally recommended for Stanford type A aortic dissection. On the other hand, resting antihypertensive therapy has been the standard treatment for acute type B dissection. Complicated type B aortic dissection having impending rupture, organ ischemia, propagation of the dissection, or continued pain should be treated by surgical repair at acute phase. Patients presenting with uncomplicated acute type-B aortic dissection (UATBAD) are typically treated conservatively. Medical management is associated with excellent results, with an in-hospital death rate of $10 \%$ [1] [2]. However, the long-term prognosis of these patients is far less favorable, including enlargement of the aorta in $73.3 \%$ of patients treated with medical therapy [3], and mortality rates ranging from $21 \%$ to $36 \%$ after 5 years [4] [5] [6].

To improve the long-term outcome, a more patient-specific approach is warranted for patients who are at high risk of developing aortic adverse events: enlargement of the aortic diameter, malperfusion, aortic rupture, and type A aortic dissection. Therefore, early and reproducible methods for assessing the risk of aortic enlargement are needed to differentiate patients who will benefit from prophylactic intervention from those who can safely receive lifelong medical treatment. The purpose of this study was to determine the association of clinical and imaging-based morphological and functional features. We analyzed correlate changes in the true and false lumen area obtained during the index hospitalization with late adverse events in patients with initially uncomplicated type B aortic dissection using computed tomography (CT) area measurements.

\section{Patients and Methods}

The Yamagata university hospital institutional review board approved for this study. Informed consent was obtained from participating patients in accordance with hospital policy.

Between July 2004 and October 2017, 334 patients with acute aortic dissection were treated at our institution. Of these, 154 patients were admitted with a diagnosis of type B acute aortic dissection. Exclusion criteria were traumatic dissection, aortic diameter more than $60 \mathrm{~mm}$, emerging aortic complications; rupture, organ ischemia, and type A dissection with 2 weeks from the onset. Twenty five patients were excluded for having these complications. Of these, 9 patients showed traumatic dissection. In the 25 patients, nine were underwent graft replacement, seven were performed TEVAR, one patient was underwent axillo-femoral bypass and another five were operated by femoro-femoral bypass. Only three patients could not receive surgery. Twenty one patients were survived after treatment, but four patients died. Ultimately, 120 medically treated patients were enrolled in the study (Figure 1). After 2 weeks of medical management, 
patients were divided into four groups according to the status of the false lumen (FL, patent or thrombosed) and aortic enlargement (enlarged or unenlarged) (Figure 2).

Acute uncomplicated Stanford type B aortic dissection is defined as a dissection not involving the ascending aorta, presenting within 14 days of symptom onset. We divided the time course of aortic dissection into acute ( $<14$ days), sub-acute (15 - 90 days), and chronic ( $>90$ days) phases. All patients were initially treated with medical management and followed up according to the standard clinical regimen. All patients received an arterial pressure catheter, central venous catheter, intravenous agents and continuous monitoring of vital signs. For blood pressure control, all patients received an intravenous calcium-channel blocker, nitroglycerine, $\beta$-blockers or a combination after admission. For the first 2 weeks after onset, systolic blood pressure was controlled to less than 120 $\mathrm{mmHg}$ with careful observation of urine output. After 2 weeks, blood pressure was controlled to less than $130 \mathrm{mmHg}$. On admission, patients were treated in an intensive care unit or high care unit. All patients underwent contrast CT scanning at emergency admission, and again on the $1^{\text {st }}$ and $7^{\text {th }}$ days after admission. All patients were administered oral medications starting the $1^{\text {st }}$ day after CT screening, and were encouraged to take a short walk starting the $7^{\text {th }}$ day after onset. Patients were eligible for discharge 4 weeks after onset. During follow-up, patients who had an aortic event despite medical management underwent aortic interventions. The term "aortic event" included enlargement of the aortic diameter, malperfusion, aortic rupture, and type A aortic dissection.

The initial diagnostic CT scans and all follow-up CT scans obtained during the chronic phase of aortic dissection were retrospectively reviewed. For all patients in this study, a baseline CT angiography (CTA) was available for review (120 scans). A total of 118 scans were available for follow-up CT analysis (excluding 2 patients in Group TU). Of the 118 follow-up scans, 114 were CTA studies and four were unenhanced CT studies ( 3 patients in Group TU, 1 patient in

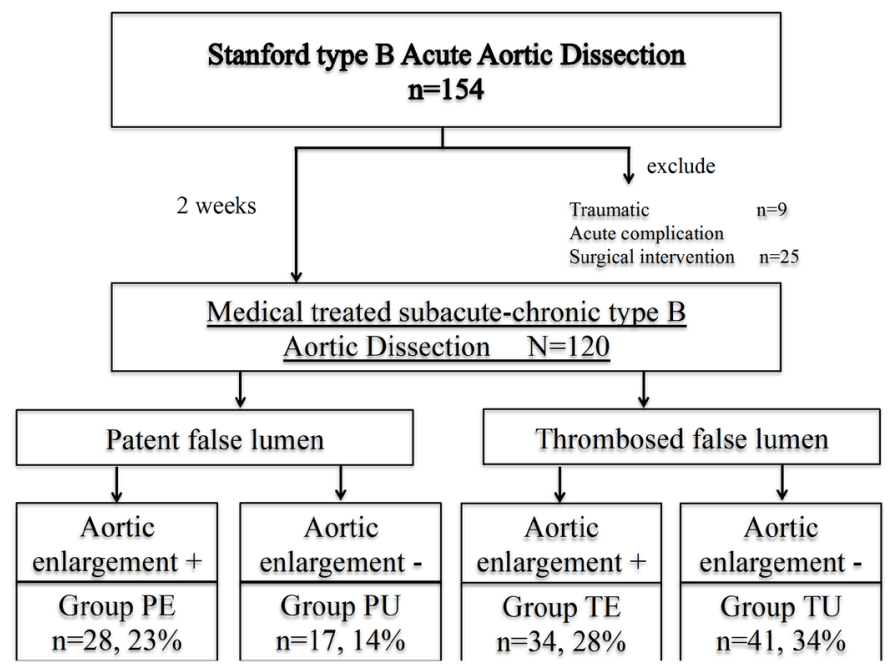

Figure 1. Summary flow diagram of deviation of study population. 

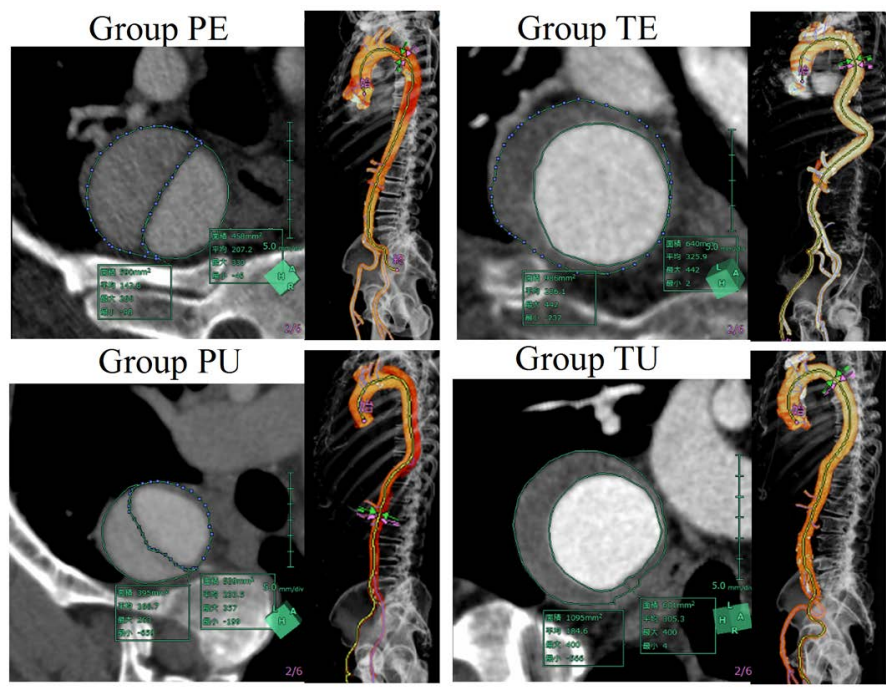

Figure 2. The typical image of CT, each case of PE, PU, TE and TU (PE: patent false lumen and aortic diameter enlargement; PU: patent false lumen and unchanged aortic diameter; TE: thrombosed false lumen and aortic diameter enlargement; TU: thrombosed false lumen and unchanged aortic diameter).

Group PU). The four unenhanced CT studies were follow-up studies obtained during the chronic phase and were used only for aortic diameter measurements and not for measurements of the true and false lumina.

Image analysis was performed on a SYNAPSE VINCENT system (Tokyo Japan, FUJIFILM Holding Corporation) with a dedicated 3D image analyzer. All CTA measurements were obtained using multiplanar reconstruction (MPR) images in an axial plane perpendicular to the aortic median centerline (Figure 3A). The aortic median centerline was generated by software on the VINCENT that uses a 3D algorithm to create an MPR centered around the contrast-enhanced aortic lumen. In all cases in which the aortic diameter was measured from an unenhanced CT scan, the unenhanced study was compared with prior contrast-enhanced CTA to define the region of dissected aorta. In no instance did the maximum aortic diameter occur in a nondissected segment.

The areas of the true and false lumina were measured. Measurements were performed on the orthogonal cross-section in which the aortic diameter was maximal (Figure 3B and Figure 3C). The maximum aortic diameter was compared between images obtained on admission and images obtained during the chronic phase. In the PU and TU groups, the first and last CTA were analyzed.

The status of the false lumen on imaging was classified as patent if flow was present in the absence of thrombus, as partially thrombosed if both flow and thrombus were present, or as completely thrombosed if no flow was present [7]. The judgement of the "thrombosed" or "partial thrombosed" was checked in the late phase of enhanced CT-scans.

Intramural hematomas and penetrating aortic ulcers were not included in this study. Ulcerlike projection type was included in the patent false lumen type following the definition of the last Japanese guideline in 2011 [8] [9]. 


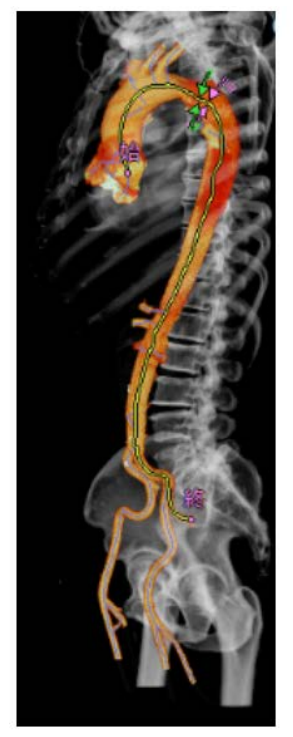

A

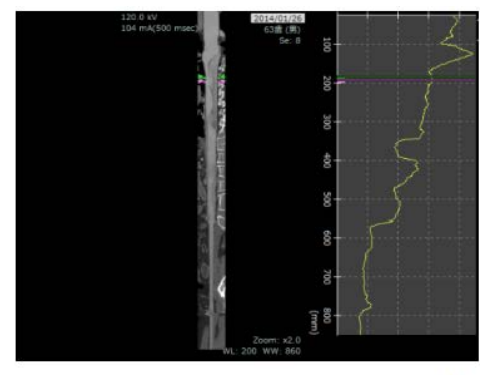

B

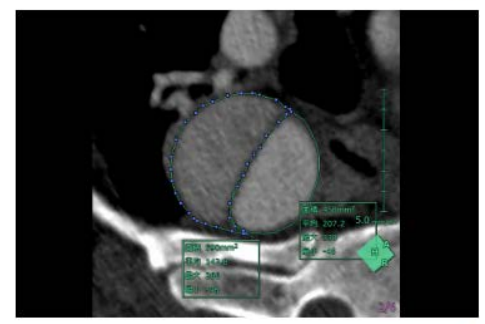

C

Figure 3. Multiplanar CT angiography reconstruction for aortic measurements in a 59-year-old man at initial hospitalization. A: The 3D image of the aorta after generation of an aortic centerline from proximal aortic arch to the left iliac artery by software on the VINCENT; B: The aorta is straightened along its centerline and the diameter of enhanced area; C: True and false lumen measurements using measurement tool, perpendicular to contour of initial flap.

\section{Statistical Methods}

Baseline patient characteristics for the total study population and the four groups (PE, PU, TE, and TU) were described as absolute numbers, percentages, and mean ( \pm standard deviation) for categorical variables. Differences between groups were evaluated using the $\chi^{2}$ test for populations and the $t$ test for independent samples of continuous variables (if normally distributed). Cumulative probabilities of event-free survival from aortic adverse events at 1 year, 5 years, and 10 years after onset were calculated with Kaplan-Meier survival analysis. The event-free curves from each group were compared by log-rank test. Aortic-related death-free curves from each group were compared by log-rank test. Analyses were conducted with JMP software, version 10 (SAS Institute).

\section{Results}

Over the 12-year study period from 2004 to 2017, 120 patients presented with uncomplicated acute type B aortic dissection. The mean age was 70 years $( \pm 11$ years) and $70 \%$ were men. The average follow-up time was $57 \pm 43$ months (range, 1 - 156 months). In addition, 90\% patients were followed up for at least 1 month. The false lumen was found to be patent in 31 patients (25.8\%), partially thrombosed in 14 (11.7\%), and completely thrombosed 75 (62.5\%). Three patients had connective tissue diseases, including Marfan syndrome, and all three were in group PE. In the PE vs. PU and the TE vs. TU analyses, there were no significant between-group differences in patient characteristics (Table 1). Both 
the PE and TE groups had significant differences in max diameter during follow-up and in the aortic growth rate. The PE group had a higher number of intimal tears than the PU group (Table 2). During the subacute-to-chronic phase, there were no significant differences in aortic related events or mortality in the PE vs. PU or the TE vs. TU groups.

In the late stage, aortic rupture was only observed in the enlarged groups, and all four patients with aortic rupture died (Table 3). Two patients were treated with thoracic endovascular aortic repair (TEVAR); one was in PE group and the other was in TE group, and the other two patients refused surgical intervention. One of the four patients had an aorto-bronchial fistula (PE group), and another had an aorto-esophageal fistula (TE group). Both patients with type A aortic dissection were treated with graft replacement; one was in TE group and another one was in TU group. In these patients, no additional aortic intervention was required. A higher rate of aortic related event was observed in the aortic enlargement groups than in the unchanged groups (Figure 4). Aortic related deaths only occurred in the enlarged groups, among which there were no significant between-group differences (Figure 5).

Comparing the PE vs PU groups, the average FL area in the PE group was significantly larger in the follow-up period. This finding suggests that, in patients with chronic type B aortic dissection with a patent FL, aortic enlargement might also increase the size of the FL (Figure 6). In the TE vs. TU groups, the average TL area of the TE group was larger in the follow-up period. Hence, in patients with a thrombosed FL, the etiology of aortic enlargement may be different than in patients with a patent FL. We also observed a significant difference in the area of the FL between the TE and TU groups, suggesting a decrease in the FL area in the TU group (Figure 6).

Table 1. Baseline Patient Characteristics $(\mathrm{PE}=$ patent false lumen and aortic diameter enlargement; $\mathrm{PU}=$ patent false lumen and unchanged aortic diameter; $\mathrm{TE}=$ thrombosed false lumen and aortic diameter enlargement; $\mathrm{TU}=$ thrombosed false lumen and unchanged aortic diameter; SD = Standard Deviation; BMI = Body Mass Index; COPD = Chronic Obstructive Pulmonary Disease). Group PE and PU were younger than Group TE and TU. There was no statistical difference between Group PE and PU, Group TE and TU. All Marfan syndrome wereincluded in Group PE. There was no statistical difference in numbers of patients diagnosed with COPD between Group PE and PU, Group TE and TU.

\begin{tabular}{|c|c|c|c|c|c|c|c|}
\hline Characteristic & $\begin{array}{c}\text { Total } \\
(\mathrm{N}=120)\end{array}$ & $\begin{array}{c}\text { Group PE } \\
(\mathrm{N}=28)\end{array}$ & $\begin{array}{c}\text { Group PU } \\
(\mathrm{N}=17)\end{array}$ & $\begin{array}{c}\text { p Value } \\
\text { (PE vs. PU) }\end{array}$ & $\begin{array}{l}\text { Group TE } \\
(\mathrm{N}=34)\end{array}$ & $\begin{array}{c}\text { Group TU } \\
(\mathrm{N}=41)\end{array}$ & $\begin{array}{c}\text { p Value } \\
\text { (TE vs. TU) }\end{array}$ \\
\hline Age, $y$, Mean \pm SD & $70 \pm 11$ & $65 \pm 13$ & $66 \pm 10$ & 0.583 & $71 \pm 9$ & $73 \pm 10$ & 0.412 \\
\hline Male, $\%$ & $70(84$ of 120$)$ & $64(18$ of 28$)$ & $76(13$ of 17$)$ & 0.513 & $74(25$ of 34$)$ & $68(28$ of 41$)$ & 0.799 \\
\hline Height, $\mathrm{cm}$, Mean \pm SD & $160.4 \pm 10.5$ & $162.1 \pm 10.3$ & $159.8 \pm 14.2$ & 0.532 & $160.8 \pm 8.9$ & $162.1 \pm 10.6$ & 0.589 \\
\hline Weight, kg, Mean \pm SD & $60 \pm 14$ & $58.8 \pm 15.4$ & $60.5 \pm 14.4$ & 0.732 & $61.6 \pm 12.6$ & $59.9 \pm 14.3$ & 0.575 \\
\hline BMI, $\mathrm{kg} / \mathrm{m}^{2}$, Mean $\pm \mathrm{SD}$ & $23 \pm 4$ & $22 \pm 4$ & $23 \pm 1$ & 0.27 & $24 \pm 4$ & $23 \pm 4$ & 0.262 \\
\hline Marfan Syndrome, \% & $3(3$ of 120$)$ & $11(3$ of 28$)$ & $0(0$ of 17$)$ & - & $0(0$ of 34$)$ & $0(0$ of 41$)$ & - \\
\hline COPD, \% & $38(32$ of 120$)$ & $43(12$ of 28$)$ & $35(6$ of 17$)$ & 0.757 & $29(10$ of 34$)$ & $26(10$ of 39$)$ & 0.796 \\
\hline $\begin{array}{l}\text { Follow-Up Period, } \\
\text { Months, Mean } \pm \text { SD }\end{array}$ & $57 \pm 43$ & $64 \pm 45$ & $42 \pm 38$ & 0.093 & $65 \pm 43$ & $51 \pm 41$ & 0.159 \\
\hline
\end{tabular}


Table 2. Initial computed tomography findings.

\begin{tabular}{|c|c|c|c|c|c|c|c|}
\hline Characteristic & $\begin{array}{c}\text { Total } \\
(\mathrm{N}=120)\end{array}$ & $\begin{array}{c}\text { Group PE } \\
(\mathrm{N}=28)\end{array}$ & $\begin{array}{c}\text { Group PU } \\
(\mathrm{N}=17)\end{array}$ & $\begin{array}{c}\text { p Value } \\
\text { (PE vs. PU) }\end{array}$ & $\begin{array}{c}\text { Group TE } \\
(\mathrm{N}=34)\end{array}$ & $\begin{array}{c}\text { Group TU } \\
(\mathrm{N}=41)\end{array}$ & $\begin{array}{c}\text { p Value } \\
\text { (TE vs. TU) }\end{array}$ \\
\hline \multicolumn{8}{|l|}{ Aortic Diameter, mm } \\
\hline On Admission & $38 \pm 7$ & $39 \pm 8$ & $37 \pm 10$ & 0.354 & $38 \pm 6$ & $37 \pm 6$ & 0.391 \\
\hline During Follow-Up (Max Diameter) & $40 \pm 9$ & $45 \pm 2$ & $35 \pm 9$ & $<0.001$ & $44 \pm 9$ & $36 \pm 6$ & $<0.001$ \\
\hline Aortic Growth Rate (mm/6 Months) & $2.0 \pm 5.7$ & $4.7 \pm 5.9$ & $-0.1 \pm 1.0$ & $<0.005$ & $5.1 \pm 5.5$ & $-1.7 \pm 4.5$ & $<0.001$ \\
\hline Perfused with Partial Thrombosiss, $\%$ & $12(14$ of 120$)$ & $25(7$ of 28$)$ & $41(7$ of 17$)$ & 0.326 & & & \\
\hline $\begin{array}{l}\text { Number of Intimal Tears } \\
\text { (Patent False Lumen) }\end{array}$ & $2.2 \pm 1.2$ & $2.5 \pm 0.2$ & $1.7 \pm 0.3$ & $<0.05$ & - & - & - \\
\hline
\end{tabular}

Table 3. Late major adverse events and aortic adverse events of uncomplicated type B aortic dissection ( $\mathrm{PE}=$ patent false lumen and aortic diameter enlargement; $\mathrm{PU}=$ patent false lumen and unchanged aortic diameter; TE = thrombosed false lumen and aortic diameter enlargement; $\mathrm{TU}=$ thrombosed false lumen and unchanged aortic diameter).

\begin{tabular}{|c|c|c|c|c|c|c|c|}
\hline Characteristic & $\begin{array}{c}\text { Total } \\
(\mathrm{N}=120)\end{array}$ & $\begin{array}{l}\text { Group PE } \\
(\mathrm{N}=28)\end{array}$ & $\begin{array}{l}\text { Group PU } \\
(\mathrm{N}=17)\end{array}$ & $\begin{array}{c}\text { p Value } \\
(\mathrm{PE} \text { vs. } \mathrm{PU})\end{array}$ & $\begin{array}{l}\text { Group TE } \\
(\mathrm{N}=34)\end{array}$ & $\begin{array}{l}\text { Group TU } \\
(\mathrm{N}=41)\end{array}$ & $\begin{array}{c}\text { p Value } \\
\text { (TE vs. TU) }\end{array}$ \\
\hline Aortic Related Deaths, \% & $4(5$ of 120$)$ & $7(2$ of 28$)$ & $0(0$ of 17$)$ & 0.519 & $9(3$ of 34$)$ & $0(0$ of 41$)$ & 0.086 \\
\hline Surgical Intervention, \% & $28(33$ of 120$)$ & $54(15$ of 28$)$ & 24 (4 of 17$)$ & 0.066 & $32(11$ of 34$)$ & $7(3$ of 41$)$ & $<0.01$ \\
\hline $\begin{array}{l}\text { Aortic Related Events } \\
\text { (without Aortic Enlargement), \% }\end{array}$ & $6(7$ of 120$)$ & $7(2$ of 28$)$ & $0(0$ of 17$)$ & 0.519 & $6(2$ of 34$)$ & $0(0$ of 41$)$ & 0.202 \\
\hline Rupture, \% & $3(4$ of 120$)$ & $7(2$ of 28$)$ & $0(0$ of 17$)$ & 0.519 & $6(2$ of 34$)$ & $0(0$ of 41$)$ & 0.202 \\
\hline Type A Aortic Dissection, \% & $2(2$ of 120$)$ & $0(0$ of 28$)$ & $0(0$ of 17$)$ & - & $3(1$ of 34$)$ & $2(1$ of 41$)$ & - \\
\hline Malperfusion, \% & $1(1$ of 120$)$ & $4(1$ of 28$)$ & $0(0$ of 17$)$ & - & $0(0$ of 34$)$ & $0(0$ of 41$)$ & - \\
\hline
\end{tabular}

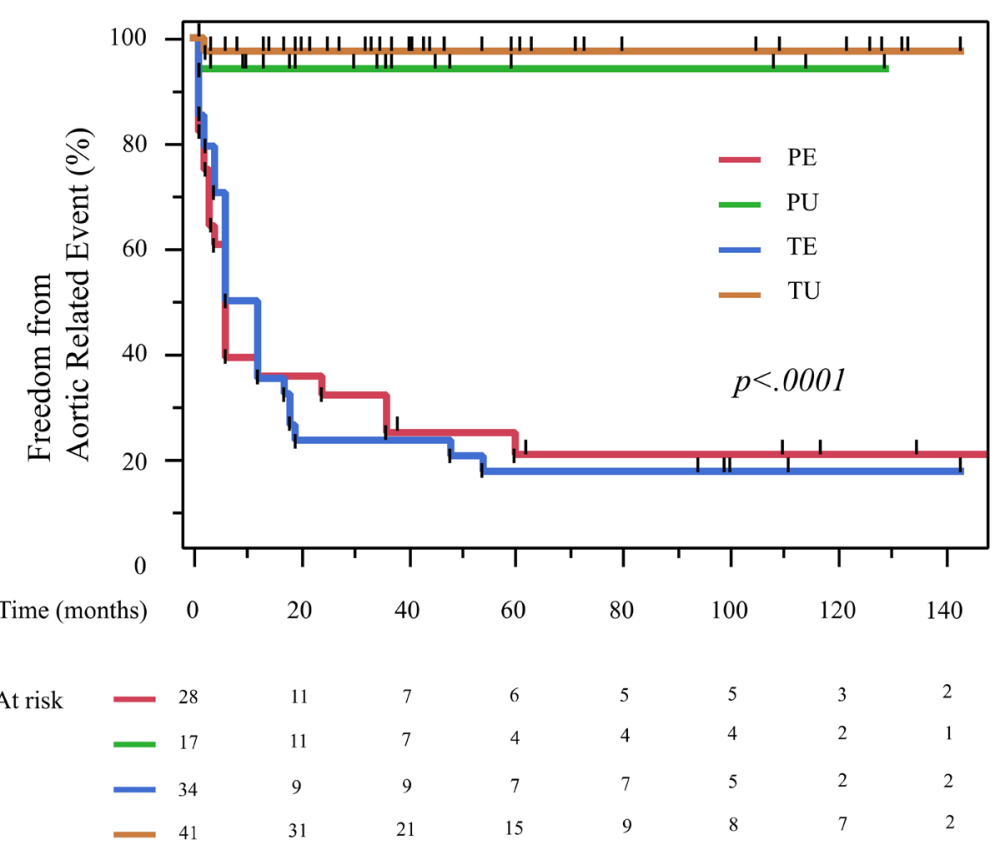

Figure 4. Kaplan-Meier curves for aortic-related event-free in 120 patients with uncomplicated chronic type B aortic dissection (uCTBAD). There were statistically significant difference between Group PE and PU, Group TE and TU $(\mathrm{p}<0.0001)$. 


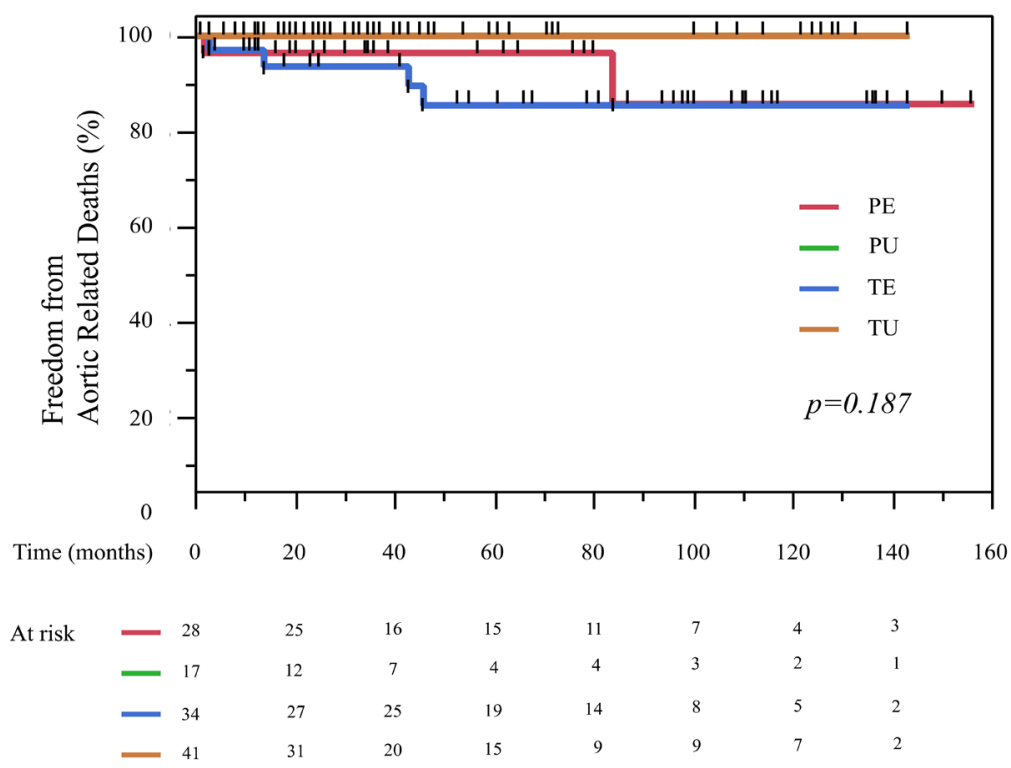

Figure 5. Kaplan-Meier curves for aortic-related deaths-free in 120 patients with uncomplicated chronic type B aortic dissection (uCTBAD).

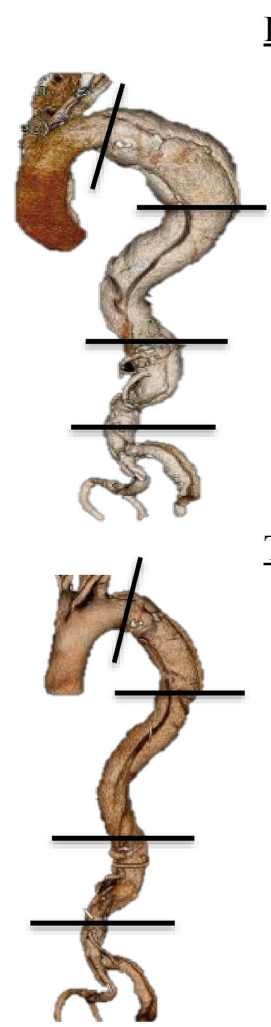

\section{PE group}

True lumen

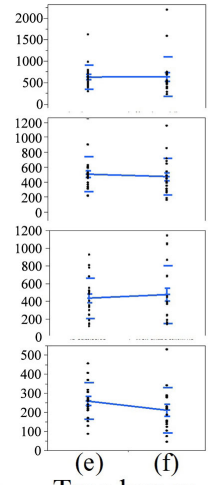

TE group

(a)

(b)

(c)

(d)

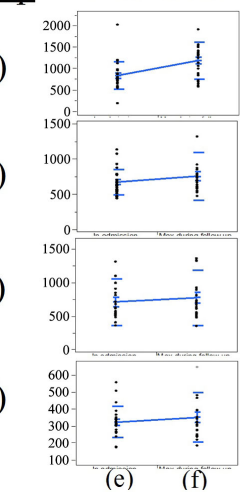

False lumen

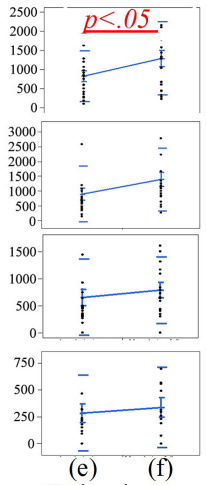

False lumen

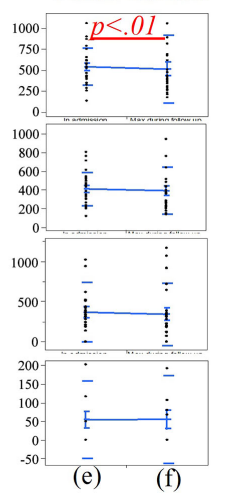

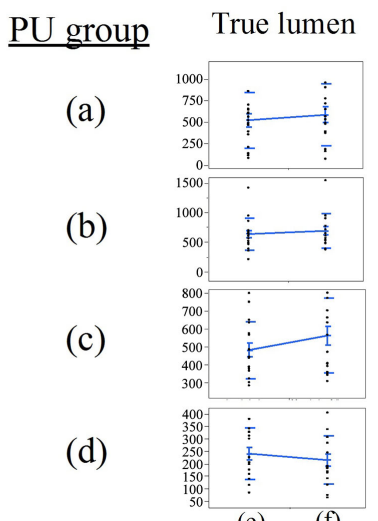

(e) (f)

$\underline{\text { TU group }}$

(a)

(b)

(c)

(d)

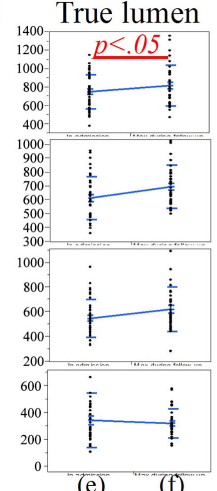

False lumen

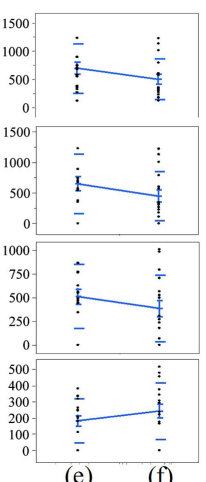

(e) (f)

False lumen

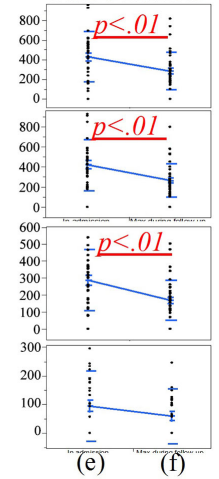

Figure 6. The chronological changes in the true and false lumen areas in all four groups ( $\mathrm{PE}=$ patent false lumen with aortic diameter enlargement; $\mathrm{PU}=$ patent false lumen with unchanged aortic diameter; TE = thrombosed false lumen with aortic diameter enlargement; $\mathrm{TU}=$ thrombosed false lumen with unchanged aortic diameter). Enhanced $\mathrm{CT}$ measurements were performed in four sections of the thoracoabdominal aorta: $2 \mathrm{~cm}$ distal to the left subclavian artery (a); the same height as the bifurcation of the trachea (b); above the celiac artery (c); $2 \mathrm{~cm}$ distal to the lower side of the renal artery (d). The mean values of the initial (e) and follow-up (f) aortic areas are connected by blue lines, and these values were compared statistically. 


\section{Discussion}

Factors that predict aortic events and mortality in patients with chronic type B aortic dissection include male sex [10], partial thrombosis of the false lumen [11], younger age [7] [12] [13], a primary entry tear located on the concavity of the distal aortic arch, dissection entry tears $>10 \mathrm{~mm}$ [14] [15] and aortic diameter $>40 \mathrm{~mm}$ [12] [16]. These risk factors are indications for surgical intervention. Recently reported predictive factors of aortic enlargement include the number of vessels originating from the false lumen [17] and the number of intercostal arteries [18]. However, the mechanism of aortic expansion in chronic aortic dissection remains unclear. It has been suggested that aortic expansion is caused by a complex interplay between three dimensional morphologic changes and the number and diameter of intimal tears, blood pressure, aortic diameter, degenerative changes of the aortic wall, etc. Our study adds to this list by demonstrating that aortic enlargement is associated with changes in the diameter of the true and false lumen, depending on the patency of the false lumen. By comparing area measurements, we may be able to differentiate patients who require aortic repair versus those who require medical treatment alone.

Kelly et al. [19] suggested that enlargement of the aortic diameter during the chronic phase of type B aortic dissection was primarily due to the increasing size of the FL; the wall of the FL had lost its muscle barrier against blood pressure. Williams et al. [20] showed in an in vitro model of chronic type B aortic dissection that the aortic diameter expands because of the dissected, elastin-poor, pressurized FL. Our findings are consistent with both of these studies. Interestingly, patients with a thrombosed FL and enlarged aortic diameter had a characteristic increase in TL diameter. Anna et al. [21] reported that more than one half of patients with intramural hematoma showed resorption of the hematoma with the first year. However, in patients in whom the hematoma did not resolve and who had an initial aortic diameter $>40 \mathrm{~mm}$, there was an increased risk of unfavorable evolution. Consistent with this finding, we found that patients with a thrombosed FL without aortic enlargement had less aortic related death and required fewer surgical interventions. The mechanism of aortic expansion in patients with a thrombosed FL may not be the same as that in patients with a patent FL. Hence, optimal preemptive treatment and timing of intervention may not be the same in these two patient populations.

We found that enlargement of the FL in patients with a patent FL, and enlargement of the TL in patients with a thrombosed FL, was correlated with aortic expansion in the chronic phase of disease. These patients require careful observation in the subacute and chronic phases.

\section{Conclusion}

In patients with $\mathrm{UATBAD}$ and a thrombosed FL, the patients with aortic enlargement tended to be increased TL size. In contrast, in patients with a patent FL, the patients with aortic enlargement tended to be increased FL size. 


\section{Limitation}

Our study is limited by its retrospective design, its relatively small number of patients, incomplete follow-up (10\%), and varying number of CT scans among patients.

\section{Conflicts of Interest}

The authors declare no conflicts of interest regarding the publication of this paper.

\section{References}

[1] Hagan, P.G., Nienaber, C.A., Isselbacher, E.M., Bruckman, D., Karavite, D.J., Russman, P.L., et al. (2000) The International Registry of Acute Aortic Dissection (IRAD): New Insights into an Old Disease. JAMA, 283, 897-903. https://doi.org/10.1001/jama.283.7.897

[2] Suzuki, T., Mehta, R., Ince, H., Nagai, R., Sakomura, Y., Weber, F., et al. (2003) Clinical Profiles and Outcomes of Acute Type B Aortic Dissection in the Current Era: Lessons from the International Registry of Aortic Dissection (IRAD). Circulation, 108, 312-317. https://doi.org/10.1161/01.cir.0000087386.07204.09

[3] Rossella, F., Montgomery, D., Lovato, L., Kische, S., Di Eusanio, M., Ince, H., et al. (2013) Survival after Endovascular Therapy in Patients with Type B Aortic Dissection. JACC. Cardiovascular Interventions, 6, 876-882.

[4] Kaji, S., Akasaka, T., Katayama, M., Yamamuro, A., Yamabe, K., Koichi, T., et al. (2003) Prognosis of Retrograde Dissection from the Descending to the Ascending Aorta. Circulation, 108, II-300-II-306. https://doi.org/10.1161/01.cir.0000087424.32901.98

[5] Marui, A., Mochizuki, T., Mitsui, N., Koyama, T., Kimura, F., Horibe, M., et al. (1999) Toward the Best for Uncomplicated Patients with Type B Acute Aortic Dissection. Circulation, 100, II-275-II-280.

[6] Akutsu, K., Nejima, J., Kiuchi, K., Sasaki, K., Ochi, M., Tanaka, K., et al. (2004) Effects of Patent False Lumen on Long-Term Outcome of Type B Acute Aortic Dissection. European Journal of Cardio-Thoracic Surgery, 26, 359-366. https://doi.org/10.1016/j.ejcts.2004.03.026

[7] Tsai, T.T., Evangelista, A., Nienaber, C.A., Myrmel, T., Meinhardt, G., Cooper, J.V., et al. (2007) Partial Thrombosis of the False Lumen in Patients with Acute Type B Aortic Dissection. The New England Journal of Medicine, 357, 349-359. https://doi.org/10.1056/NEJMoa063232

[8] Matsuo, H. (1998) Thrombosed Type of Aortic Dissection-Its Clinical Features and Diagnosis. International Journal of Angiology, 7, 329-334.

[9] Komoto, S., Ishimaru, A., Ueda, Y., Ohki, T., Okita, Y., Ogino, H., et al. (2011) Guidelines for Diagnosis and Treatment of Aortic Aneurysm and Aortic Dissection. http://www.j-circ.or.jp/guideline/pdf/JCS2011_takamoto_h.pdf

[10] Tolenaar, J.L., van Keulen, J.W., Jonker, F.H., van Herwaarden, J.A., Verhagen, H.J., Moll, F.L., et al. (2013) Morphologic Predictors of Aortic Dilatation in Type B Aortic Dissection. Journal of Vascular Surgery, 58, 1220-1225. https://doi.org/10.1016/j.jvs.2013.05.031

[11] Loewe, C., Czerny, M., Sodeck, G.H., Ta, J., Schoder, M., Funovics, M., Dumfarth, J., et al. (2012) A New Mechanism by Which an Acute Type B Aortic Dissection Is 
Primarily Complicated, Becomes Uncomplicated, or Remains Uncomplicated. The Annals of Thoracic Surgery, 93, 1215-1222. https://doi.org/10.1016/j.athoracsur.2011.12.020

[12] van Bogerijen, G.H., Tolenaar, J.L., Rampoldi, V., Moll, F.L., van Herwaarden, J.A., Jonker, F.H., et al. (2014) Predictors of Aortic Growth in Uncomplicated Type B Aortic Dissection. Journal of Vascular Surgery, 59, 1134-1143. https://doi.org/10.1016/j.jvs.2014.01.042

[13] Luebke, T. and Brunkwall, J. (2014) Type B Aortic Dissection: A Review of Prognostic Factors and Meta-analysis of Treatment Options. Aorta, 2, 265-278. https://doi.org/10.12945/j.aorta.2014.14-040

[14] Cambria, R.P. and Conrad, M.F. (2016) Thoracic Endovascular Aneurysm Repair for Uncomplicated Type B Dissection. Journal of Vascular Surgery, 64, 1558-1559. https://doi.org/10.1016/j.jvs.2016.08.002

[15] Schwartz, S.I., Durham, C., Clouse, W.D., Patel, V.I., Lancaster, R.T., Cambria, R.P., et al. (2018) Predictors of Late Aortic Intervention in Patients with Medically Treated Type B Aortic Dissection. Journal of Vascular Surgery, 67, 78-84. https://doi.org/10.1016/j.jvs.2017.05.128

[16] Onitsuka, S., Akashi, H., Tayama, K., Okazaki, T., Ishihara, K., Hiromatsu, S., et al. (2004) Long-Term Outcome and Prognostic Predictors of Medically Treated Acute Type B Aortic Dissections. The Annals of Thoracic Surgery, 78, 1268-1273. https://doi.org/10.1016/j.athoracsur.2004.02.031

[17] Kamman, A.V., Brunkwall, J., Verhoeven, E.L., Heijmen, R.H. and Trimachi, S. (2017) Predictors of Aortic Growth in Uncomplicated Type B Aortic Dissection from the Acute Dissection Stent Grafting or Best Medical Treatment (ADSORB) Database. Journal of Vascular Surgery, 65, 964-971. https://doi.org/10.1016/j.jvs.2016.09.033

[18] Samuel, I.S., Christopher, D., Darrin, C., Virendra, I.P., Todd, R.L., Richard, P.C., et al. (2018) Predictors of Late Aortic Intervention in Patients with Medically Treated Type B Aortic Dissection. Journal of Vascular Surgery, 67, 78-84. https://doi.org/10.1016/j.jvs.2017.05.128

[19] Kelly, A.M., Quint, L.E., Nan, B., Zheng, J., Cronin, P., Deeb, G.M., et al. (2007) Aortic Growth Rates in Chronic Aortic Dissection. Clinical Radiology, 62, 866-875. https://doi.org/10.1016/j.crad.2007.04.006

[20] Williams, D.M., LePage, M.A. and Lee, D.Y. (1997) The Dissected Aorta. I. Early Anatomic Changes in an in Vitro Model. Radiology, 203, 23-31. https://doi.org/10.1148/radiology.203.1.9122399

[21] Sailer, A.M., Nelemans, P.J., Hastie, T.J., Chin, A.S., Huininga, M., Chiu, P., et al. (2017) Prognostic Significance of Early Aortic Remodeling in Acute Uncomplicated Type B Aortic Dissection and Intramural Hematoma. The Journal of Thoracic and Cardiovascular Surgery, 154, 1192-1200. https://doi.org/10.1016/j.jtcvs.2017.04.064 